\title{
Contribution of Satellite Remote Sensing in Environmental Monitoring at Regional Scales: a Short Review
}

\author{
Stavros Kolios* \\ Department of Physics, Greece \\ *Corresponding author: Stavros Kolios, Laboratory of Meteorology, Physics Department, 45110 Ioannina, Greece \\ Submission: 眥 February 12, 2018; Published: 眥 February 27, 2018
}

\begin{abstract}
Since its genesis, satellite remote sensing has enabled observations of environmental changes at inaccessible locations, improving tremendously many scientific fields like the meteorology, oceanography, agriculture production, glaciology, geology etc. Using the information collected by satellites, changes in the physical environment can be measured and the information is analyzed to predict future patterns and achieve better environmental outcomes in different areas. Due to its speed and efficiency in information-gathering, the applications of satellite remote sensing are continually increasing and becoming a vital part in environmental resource management process.
\end{abstract}

Keywords: Satellite remote sensing; Environment; Agriculture production; Geology

\section{Introduction}

Nowadays, the contiguous increasing improvement of the synchronous satellite sensors and the numerous satellite platforms can provide data and products of high spatiotemporal accuracy and in cost-effective way, which are essential for many scientific fields of interest and especially in the environmental studies. More specifically, the advanced capabilities of the multispectral (or hyper spectral) satellite imagery making possible to monitor spatial patterns and land use/land cover changes using methodologies and spatial analyses, providing useful information even in remotely sensed areas where ground-based observations, are completely absent. It is characteristic that nowadays, a wide range of different sensors operating in many satellite platforms, provide multispectral imagery as well as microwave information. Moreover, recently there are cases of polar-orbiting satellites which carry lidars [1-3] increasing the capabilities of satellite imagery in monitoring land/ocean/atmosphere. The increasing use of the remotely sensed images is importantly owed to the wide range of spectral regions are recorded, ranging from visible to thermal infrared (passive radiometers), the microwave sensors and satellite lidar/radar technology onboard of some synchronous satellites. These remotely sensed datasets with the companied use of the Geographical Information Systems (GIS), expand the horizon of many scientific communities which are dealing with the environment, their choices of imagery sources and their ability to detect spectral, spatial and temporal characteristics of the examined parameters and phenomena.
Focusing in the monitoring of the land surface characteristics, the modern satellite imageries have been already proven, valuable tools to monitor and mapping changes in a great variety of parameters and phenomena like vegetation quality, forest fires, urban sprawl land use/land cover changes, land degradation etc [4-6]. Furthermore, it must be mentioned that many satellite image products especially of high spatial resolution (finer than $10 \mathrm{~m}$ ), are provided at costs which in many cases are not easy to be found. Nevertheless, up to now, some satellite missions and instruments have already gained the preference of the majority of the scientist in monitoring land surface characteristics and spatiotemporal changes, because provide full image products of high quality and at no cost. Characteristic example in the Landsat satellite series. Especially the latest satellite of this series, the Landsat-8, carries the Operational Land Instrument (OLI) and the Thermal Infrared Sensor (TIRS) which provide freely available multispectral images at spatial resolution of $30 \mathrm{~m}$ and radiometric accuracy capable to capture accurately, significant land changes at local to regional scales. It is also important to be mentioned, the case of Sentinel satellites, which can provide a huge amount of choices to monitor the environment at different spatial resolutions ranging from hundred kilometers (coarse resolution) to $10 \mathrm{~m}$ (high resolution). Another interesting satellite, is the Advanced Land Observing Satellite (ALOS) which carries-among others-the Advanced Visible and Near Infrared Radiometer (AVNIR), providing multispectral images of $10 \mathrm{~m}$ spatial resolution. Conclusively, it can be said that although the abovementioned satellites and sensors are 
widely used in the international bibliography, consist just some among numerous sun-synchronous satellites which are operating nowadays and can be used to monitor land surface characteristics [7-9].

\section{Conclusion}

Continuing the uncontested usefulness of satellite remote sensing in the environmental monitoring, a new era has already started through the use of modern satellite sensors which provide multispectral and hyperspectral images of continuously increasing spatial accuracy and radiometric quality as well as synchronous microwave and Lidar instrumentation.

\section{References}

1. Schutz BE, Zwally HJ, Shuman CA, Hancock D, DiMarzio JP (2005) Overview of the ICE Sat mission. Geophysical Research Letters 32(21): 01.

2. Popescu SC, Zhao K, Neuenschwander A, Lin C (2011) Satellite lidar vs small footprint airborne lidar: Comparing the accuracy of aboveground biomass estimates and forest structure metrics at footprint level. Remote Sensing of Environment 115(11): 2786-2797.

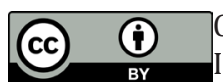

Creative Commons Attribution 4.0

nternational License

For possible submissions Click Here
3. Papagiannopoulos N, Mona L, Alados-Arboledas L, Amiridis V, Baars H, et al. (2016) CALIPSO climatological products: evaluation and suggestions from EARLINET. Atmospheric Chemistry and Physics 16(4): 234-2357.

4. Stavros K, Chrysostomos D, Stylios (2013) Identification of land cover/ land use changes in the greater area of the Preveza peninsula in Greece using Lands at satellite data. Applied Geography 40: 150-160.

5. Jafari R, Bakhshandehmehr L (2013) Quantitative mapping and assessment of environmentally sensitive areas to desertification in central Iran. Land Degradation and Development 27: 108-119.

6. Sepehr A, Zucca C, Nowjavan MR (2014) Desertification status using factors representing ecological resilience. British Journal of Environment and Climate Change 4(3): 279-291.

7. Banzhaf E, Grescho V, Kindler A (2009) Monitoring urban to peri-urban development with integrated remote sensing and GIS information: a Leipzig, Germany case study. International Journal of Remote Sensing 30(7): 1675-1696.

8. Petropoulos PG, Kontoes C, Keramitsoglou I (2011) Burnt area delineation from a uni-temporal perspective based on Landsat TM imagery classification $\mathrm{u}$ sing Support Vector Machines. International Journal of Applied Earth Observation and Geoinformation 13: 70-80.

9. Thapa RB, Murayama Y (2009) Urban mapping, accuracy, \& image classification: A comparison of multiple approaches in Tsukuba City, Japan. Applied Geography 29: 135-144.

\section{Your subsequent submission with Crimson Publishers will attain the below benefits}

- High-level peer review and editorial services

- Freely accessible online immediately upon publication

- Authors retain the copyright to their work

- Licensing it under a Creative Commons license

- Visibility through different online platforms

- Global attainment for your research

- Article availability in different formats (Pdf, E-pub, Full Text)

- Endless customer service

- Reasonable Membership services

- Reprints availability upon request

- One step article tracking system 